\title{
MAPEANDO UMA ESCOLA: TEXTO E CONTEXTO ATRAVESSADO POR PRÁTICAS DE EDUCAÇÃO AMBIENTAL
}

\author{
Juliana Schwingel Gasparotto ${ }^{1}$ \\ Nádia Geisa Silveira de Souza ${ }^{2}$ \\ ${ }^{1}$ Universidade Federal do Rio Grande do Sul; j.gasparotto@yahoo.com.br \\ ${ }^{2}$ Universidade Federal do Rio Grande do Sul; nadiags@terra.com.br
}

\section{RESUMO}

Este trabalho tem a finalidade de apresentar parte do movimento que realizei na minha pesquisa de mestrado, vinculada ao Programa de Pós-Graduação em Educação e Ciências: Química da Vida e Saúde/UFRGS, na qual procuro olhar as práticas de Educação Ambiental postas em funcionamento no cotidiano de uma escola. Considerando questões centrais das versões pós-estruturalistas dos Estudos Culturais e proposições de Foucault, interroguei acerca dos discursos de Educação Ambiental que circulam naquele espaço escolar. Discuto como a escola lida com o discurso ambiental nas práticas escolares cotidianas e seus possíveis efeitos no modo de pensar e agir dos sujeitos/alunos naquele ambiente.

Palavras-chave: Educação Ambiental, Estudos Culturais, práticas discursivas, sujeitos/alunos/ecológicos

\begin{abstract}
This paper aims to present part of the movement that I made in my Master thesis, linked to the Graduate Program in Education and Sciences: Chemistry of Life and Health / UFRGS, in which I try to look at the environmental education practices put in place the daily life of a school. Considering the central questions of poststructuralist versions of Cultural Studies and propositions of Foucault, questioned about the speeches of Environmental Education circulating at the school. I discuss how the school deals with the environmental discourse in everyday school practices and their possible effects on thinking and acting of the subjects / students in that environment.
\end{abstract}

Key words: Environmental education, Cultural Studies, discursive practices, characters/ students / ecological, school

\section{INTRODUÇÃO}

Ao pensar a minha chegada na escola e os movimentos que empreendi para observar os acontecimentos desse lugar, compreendo as múltiplas tensões que, conforme Tavares (2003, p.43), “envolvem o/a pesquisador/a em seus movimentos de chegada à escola e tentativa de registro minucioso do que pretende observar/investigar". Por ser professora, várias vezes, deparei-me com a angústia de talvez não enxergar, ou correr o risco de direcionar meu "olhar" a partir do meu fazer pedagógico, fato que bem descreve Veiga-Neto (2002, p.36) ao falar da 
[...] questão da total impossibilidade do distanciamento e da assepsia metodológica ao lançar nossos olhares sobre o mundo. Isso não significa falta de rigor, mas significa que devemos ter sempre presente que somos irremediavelmente parte daquilo que analisamos e que, tantas vezes, queremos modificar.

Quero ressaltar o fato de reconhecer que ao escrever aqui o que vi, enquanto estive la $^{l}$, estou narrando o outro [a escola e seus atores sociais], numa versão que será minha, pois lá se estabeleceu uma constante negociação e produção de significados (GOTTSCHALK, 1992), onde eu, como pesquisadora, passei a produzir meus próprios dados (CALDEIRAS, 1988). Isso, por entender que os dados não são algo que estão lá, esperando para ser coletado, mas são produzidos a partir de relações de saber/poder. Nessa linha reflexiva, ao me referir às relações de poder, estou baseando-me nas concepções de Foucault, que se apresentam discutidas em Machado (2008, p.XIV), para quem

[...] os poderes não estão localizados em nenhum ponto específico da estrutura social. Funcionam como uma rede de dispositivos ou mecanismos a que nada ou ninguém escapa, a que não existe exterior possível, limites ou fronteiras. Daí a importante e polêmica ideia de que o poder não é algo que se detém como uma coisa, como uma propriedade, que se possui ou não. Não existe de um lado os que têm o poder e de outro aqueles que se encontram dele alijados. Rigorosamente falando, $o$ poder não existe; existem sim práticas ou relações de poder.

Por sua vez, Sampaio (2005, citado por MOMO, 2007) alerta que o estar lá requer um incansável questionamento sobre como se portar na relação com o outro, em que aspectos se concentrar, bem como, no que e como registrar. Então, o que escrevo $a q u i$, é resultado da minha interpretação do ter estado lá; interpretação que, a esteira de Nietzsche, é sempre inacabada (FOUCAULT, 1999)

\subsection{OLHARES, SENTIDOS, ESCOLHAS}

Parada em frente ao portão de entrada, com o olhar de estrangeiro lá estava eu, observando a escola e imaginando o que encontraria atrás do muro. Interessava-me a observação participante que realizaria nas turmas do terceiro ciclo, durante determinadas aulas, das professoras de Ciências e de Geografia. Contudo, ao atravessar

\footnotetext{
${ }^{1}$ O conhecido antropólogo Clifford Geertz (1989) utiliza a expressão Estar lá, escrever aqui como título de um artigo que abordava o "novo" papel do antropólogo após o colonialismo.
} 
os muros da escola, sabia de antemão que me colocava diante de um desafio a ser vivido - aprender a complexificar meus processos de leitura e percepção. Nesse sentido, Tavares (2003, p.46) menciona que:

\begin{abstract}
A percepção, porém, é um ato muito complexo. Coloca em ação cada um dos nossos cinco sentidos, ora mais este, ora mais aquele, na maioria das vezes todos em conjunto. E essa complexidade aumenta quando consideramos a percepção como um dispositivo cultural, produzido na e pela cultura na qual estamos imersos, e que define os nossos modos (culturais) de perceber, de ler o mundo.
\end{abstract}

Cabe ressaltar que ao "ler" a escola como um texto/contexto, vou mapeando seus espaços e movimentos de acordo com minhas captações sensoriais e, neste "olhar giroscópio" vou buscando uma apropriação concreta e simbólica, mais significativa desse espaço. Nesse sentido, enquanto observadora participante, comecei minhas "andanças interessadas" (TAVARES, 2003) pela escola, transitando por entre os mais variados espaços. Como diz a autora (op. cit.), "queria ver e ser vista, ouvir e ser ouvida, compreender e ser compreendida" (p.47); pretendia, de certa maneira, minimizar as "miras" dos olhares, tornar-me "menos estranha" neste espaço. Contudo, minha intenção era acompanhar aulas de Geografia e Ciências, em turmas do terceiro ciclo, portanto, as professoras selecionaram algumas aulas que, no seu entendimento, configuravam-se como de Educação Ambiental e foram nessas aulas que realizei minhas observações. A partir das observações dessas aulas, selecionei algumas "cenas pedagógicas" que deram suporte as minhas análises: uma saída de campo para observação do relevo e discussão sobre a ocupação humana dos espaços, uma entrevista com a professora de Ciências a respeito de uma atividade realizada com estes alunos sobre o uso adequado das lixeiras do bairro e uma dinâmica interdisciplinar abordando questões de gênero. Com este recorte, busquei compreender o processo de enunciação posto em funcionamento nestas práticas pedagógicas, associadas à Educação Ambiental. Porém, neste momento, realizo uma breve discussão a respeito de uma das cenas analisadas.

\title{
1.3 CENA PEDAGÓGICA III: LIXO, UMA QUESTÃO DE CONSCIENTIZAÇÃO?
}

Pesquisadora: Ao acompanhar uma atividade de campo com a professora de Geografia, num determinado ponto, uma aluna, ao se deparar com uma lixeira, 
manifestou indignação com o que estava vendo. Então fiquei sabendo que os alunos teriam desenvolvido um projeto sobre o lixo aqui no bairro, nas aulas de Ciências. Tu poderias falar um pouco mais sobre este trabalho? Como surgiu a ideia de trabalhar com o lixo da comunidade? O que vocês fizeram?

Professora de Ciências: Bem, os alunos comentaram que gostariam de trabalhar sobre o meio ambiente, principalmente o efeito estufa que eles ouviam e liam nos meios de comunicação e não tinham muita certeza do que era. Então, comecei a trabalhar a nossa relação com o ambiente de uma forma mais ampla. Utilizei exemplos próximos de nós, como por exemplo, o tráfico de veículos na BR 386 que todos eles conhecem. Logo percebi que vários alunos se deram conta de que nós também temos parcela de culpa no efeito estufa. Para enriquecer nosso trabalho propus um passeio pelo bairro, onde os alunos deveriam anotar em seus cadernos algo que eles considerassem um fator contribuinte para o efeito estufa. Para minha surpresa, eles relataram muita coisa, veja algumas falas: "Olha lá tem fumaça, deve ser minha vizinha queimando as folhas que varreu do pátio. Profe vamos lá falar pra ela não fazer mais isso, porque vai ficar mais calor e o ar vai ficar mais poluído!" "Fui! Olha só essa lixeira, tá fedendo!” "Profe, na lixeira da minha rua tá tudo misturado, eles nem colocam nas sacolinhas."

Deixei eles falarem tudo o que perceberam e anotaram, então surgiu a necessidade de resolver o problema que mais estava perturbando os alunos: o lixo. Iniciamos visitando nossa horta escolar que possui uma composteira, afinal de contas, o que vimos nas lixeiras foi na maioria lixo orgânico. Ali fui questionando a utilidade da composteira, todos eles sabiam que o lixo virava adubo e que poderia ser colocado na horta para deixar as verduras mais bonitas. Procurei estimular os alunos para que conversassem em casa para que o lixo orgânico fosse "enterrado", ou melhor, que quem pudesse fizesse uma composteira, afinal de contas, todos eles disseram que existe um cantinho de terra em suas casas e que isso seria possível fazer. Como esta atividade estava ocorrendo aqui na escola, percebi que eles tiveram maior sensibilidade e preocupação em realizá-la em casa também.

Falamos em coleta seletiva e qual é o dia que o caminhão passa no bairro para recolher o lixo seco. Ninguém sabia ao certo, então eu trouxe folhetos informativos do Meio Ambiente de Lajeado. Eles colaram no caderno para mostrar em casa. Para comprovar a eficiência deste trabalho, fizemos uma caminhada pelas ruas do nosso bairro, no dia da coleta seletiva, observando se realmente as pessoas só colocavam lixos secos nas lixeiras. Infelizmente só vimos lixo misturado e até solto dentro e fora da 
lixeira. Os alunos ficaram indignados com tanta bagunça e, para piorar, vimos o caminhão da coleta seletiva carregando tudo. Para quê? Para onde? O que acontece?

Convidei a funcionária Leila, do Meio Ambiente, para palestrar sobre o destino do lixo em Lajeado, com o intuito de tornar este trabalho mais aprofundado e despertar muito comprometimento nos alunos.

Conversei com os alunos sobre fazermos uma visita ao Aterro Sanitário de Lajeado, pois não é fácil conscientizar adolescentes se os adultos não aprenderam a separar seus lixos. Todos adoraram a ideia. Marcamos um dia e fomos... Chegando lá, eles se assustaram com a quantidade de lixos que viram, odiaram o cheiro, se assustaram com os urubus, garças e gaviões que estavam por ali. Quando vimos a lagoa de chorume, eles ficaram horrorizados. Acredito que foi uma grande aprendizagem, principalmente para a vida. As perguntas foram muitas, pois eles ficaram muito intrigados com a quantidade de chorume. "Profe de onde vem tanta sujeira?" "De onde vem esta gosma?" "Por que fede tanto?" "É verdade que isso polui o ambiente?" A funcionária que nos acompanhou esclareceu nossas dúvidas.

Em sala de aula procurei explorar bastante o que vimos lá. Organizamos as lixeiras das salas de aula da escola, onde cada dupla de alunos identificou as lixeiras em orgânico, seco e rejeito, mas antes disso, eles tinham que saber explicar os objetivos do nosso trabalho para cada turma que entravam, inclusive na direção da escola. A tarefa para casa foi explicar às famílias os motivos de evitar jogar os restos orgânicos na lixeira, mas sim, fazer a composteira em casa.

Durante nossas conversas, percebi que alguns comentavam que em suas casas a mãe já estava separando os lixos. Fiquei muito satisfeita com os comentários, pois eles eram diários. Senti que eles contaminaram suas famílias, o objetivo foi atingido. É claro que nem todos conseguiram convencer seus pais, mas o importante é que eles estavam cientes do que deveria ser feito. Num dia desses, alguém me questionou: "Profe, de que adianta nós separarmos o lixo da sala se as merendeiras pegam e misturam tudo na lixeira grande do corredor?" Confesso que me deu vergonha, pois no projeto, eles também instruíram as merendeiras e não estava funcionando. O que fazer? Questionei a turma e eles pediram para falar com a diretora. Foi o que fizemos. Dois alunos representaram a turma e pediram para que elas se engajassem nesse trabalho tão importante, percebi que até a diretora ficou sem graça. Passado algum tempo, pensei em fazermos uma blitz nas lixeiras do bairro, pois os alunos traziam reclamações com freqüência sobre as lixeiras mal cuidadas e lixos misturados. Organizei da seguinte 
forma: em grupos de até três pessoas, eles anotariam no caderno a situação de cada lixeira visitada, o nome da rua e o ponto exato de sua localização. Marcamos o dia e iniciamos o nosso trabalho, foi um pouco demorado, mas vistoriamos todas as lixeiras da proximidade da escola. Para nossa decepção, somente uma, das dezoito estava organizada. É...nossa, não era nada fácil! Pensamos que poderíamos envolver mais a comunidade, especialmente nossos vizinhos que ainda usavam algumas esquinas para colocar seus lixos ao invés de levar até as lixeiras. Confeccionou-se materiais solicitando a separação correta dos lixos, um grupo de alunos saiu pelas ruas e distribuiu de casa em casa. Outro grupo arregaçou as mangas, colocou luvas e recolheu todos os lixos do chão que estavam perto das lixeiras. Confesso que foi muito nojento, mas fiquei emocionada com a disposição dos alunos que não paravam, nem faziam cara feia. Quando acabaram nossos sacos de lixo, pensei que pediriam para voltar, para minha surpresa, alguém deu a ideia de pedir aos vizinhos, pois havia muito a fazer ainda e lá fomos nós...

Voltando para a escola, todos cansados, mas não ouvi nenhuma reclamação do mau cheiro, da sujeira. A sensação parecia de tarefa cumprida! Fizemos uma avaliação do nosso trabalho, onde no geral o grupo concordou para que fosse feito mais vezes, pois lhes incomodava ver tanto lixo esparramado pelo chão. Passado alguns dias, voltei a questionar sobre como estavam as "nossas lixeiras" e um aluno logo falou: "Profe, minha mãe disse que valeu a pena nosso trabalho, porque agora colocaram uma lixeira nova lá perto de casa porque aquela tava estragada e também as pessoas não estão colocando mais tanto lixo no chão."

Eu questionei o grupo a respeito do que eles achavam de poucas pessoas limpar a sujeira alheia, se cada um deve cuidar da sua. Muitos concordaram que quem suja limpa. Uma aluna comentou: "Profe, mas se eles não aprenderam, nós temos que dar o exemplo mostrando como se faz." Essa fala me deixou sem palavras, mas depois ouvi outros concordando e iniciamos uma breve discussão. Então comentei sobre o trabalho que eles já haviam iniciado, que a semente já tinha sido lançada e que com certeza veríamos os resultados, mas não imediatos, que isso exigia paciência e muita persistência. Falei que esse trabalho nunca acabaria, que ele seria contínuo em nossas vidas, que mais pessoas se engajariam com o passar do tempo...

$\mathrm{Na}$ fala da professora há diversos aspectos que apontam para a direção de uma abordagem da corrente resolutiva da Educação Ambiental, ou seja, encontra-se um 
imperativo de ação estabelecido na modificação de comportamento ou de projetos coletivos (SAUVÉ, 2005). De acordo com a autora (op. cit.), tal abordagem da Educação Ambiental adota a visão central da proposta sugerida pela UNESCO, em seu Programa Internacional de Educação Ambiental (1975-1995). A base da proposta pedagógica vem centrada no estudo de problemas ambientais, considerando os componentes sociais e biofísicos e suas controvérsias inerentes, objetivando: a identificação de uma situação-problema, pesquisa desta situação, diagnósticos, buscas de soluções, avaliação e escolha de soluções ótimas. Contudo, na maioria das vezes, para não dizermos na totalidade, a implementação das soluções não está associada a esta proposição. (SAUVÉ, 2005)

$\mathrm{Na}$ afirmação da professora - “(...) então surgiu a necessidade de resolver o problema que mais estava perturbando os alunos: o lixo." -, podemos claramente identificar a proposição que marca a corrente resolutiva de Educação Ambiental - a resolução de problemas. Além disso, toda dinâmica pedagógica utilizada ao longo do projeto está pautada nos objetivos mencionados anteriormente: identificação de uma situação-problema, pesquisa desta situação, diagnósticos, buscas de soluções, avaliação e escolha de soluções ótimas. O lixo, colocado de forma inadequada nas lixeiras do bairro, configurava-se no problema a ser resolvido. Com o "problema" determinado, a professora busca, junto com os alunos, pesquisar a situação do lixo no bairro e na cidade, desenvolvendo uma série de propostas e intervenções pedagógicas. Munidos de informações e de um determinado tipo de saber, um saber conferido e legitimado pela "Voz do especialista" - pois ao buscar "aprofundar" os conhecimentos sobre o lixo do município, a professora traz a fala de funcionárias/biólogas2 da Secretaria do Meio Ambiente para legitimar os "conhecimentos científicos" conferidos sobre o lixo -, começam as buscas de soluções para o problema.

Lyotard (2008) considera que a ciência seria um subconjunto do conhecimento, que "o saber científico não é todo o saber" (p.12), mas sim, uma espécie de discurso feito de enunciados denotativos - que vai dizer sobre o verdadeiro e o falso -, portanto, as funcionárias/biólogas acabam imbuídas, pelo "saber biologizante", de proferirem

\footnotetext{
${ }^{2}$ As funcionárias citadas pela professora são biólogas e /ou estudantes de Biologia, embora ela não tenha mencionado, eu, por ter trabalhado diretamente na Secretaria do Meio Ambiente sou conhecedora deste fato.
} 
bons enunciados denotativos, mas também bons enunciados prescritivos e avaliativos ${ }^{3}$ sobre o lixo.

Utilizando-me, ainda, das considerações de Lyotard (2008) sobre a didática, gostaria de ressaltar que, em meus entendimentos, a professora de Ciências, ao buscar em conjunto com os alunos respostas para as inquietações sobre o lixo, assume um papel de expert/pesquisadora, colocando o aluno (destinatário da didática) a par do que ela não sabe, mas busca saber, introduzindo-os "no jogo da formação do saber científico" (p.46).

Ao pensar em tais práticas de Educação Ambiental, encontro ressonância nas análises de Foucault (cit. por MACHADO, 2008), que afirma que todo o conhecimento, seja ele qual for, "só pode existir a partir de condições políticas que são as condições para que se formem tanto o sujeito quanto os domínios de saber" (p. XXI), visto que todo o saber é político e "tem sua gênese em relações de poder" (ibidem). Em meio a uma enorme quantidade de proposições a respeito das questões ambientais, de uma interminável lista de indicações, sugestões, parâmetros, regulamentos, decretos e leis (nacionais e internacionais) referentes ao ambiente e à Educação Ambiental, encontramse condições de possibilidade para emergência de novas formas de subjetividades. Nessa perspectiva, podemos dizer que as práticas de Educação Ambiental, compreendidas como práticas sociais, atravessadas por uma multiplicidade de vozes imbricadas às relações de saber/poder, integram a constituição de um determinado tipo de sujeito. Cabe ressaltar, no entanto, que ao falar do poder, Foucault acrescenta uma concepção positiva, produtiva e transformadora para o mesmo:

O que faz com que o poder se mantenha e seja aceito é simplesmente que ele não pesa só como uma força que diz não, mas que de fato ele permeia, produz coisas, induz ao prazer, forma saber, produz discurso. Deve-se considerá-lo como uma rede produtiva que atravessa todo o corpo social muito mais do que uma instância negativa que tem por função reprimir (FOUCAULT, 2008, p.8).

Vivemos um momento no qual as relações entre saber e poder criaram outros e novos conhecimentos referentes ao tratamento adequado, não só dos resíduos sólidos (lixo), mas também dos resíduos líquidos e gasosos provenientes das ações humanas. Muito se produziu e vem se produzindo em relação a técnicas ambientalmente viáveis

\footnotetext{
${ }^{3}$ A respeito dos enunciados denotativos, prescritivos e avaliativos, ver Lyotard (2008).
} 
para os processos de industrialização e urbanização. Um novo discurso surge a partir das relações de saber/poder e vem se estabelecendo com a emergência das questões ambientais - o discurso da sustentabilidade (econômica, ecológica, social e cultural). Um discurso que vai se espraiando nas mais variadas instâncias sociais, inclusive nas escolas.

Retomando minhas análises sobre as abordagens de Educação Ambiental utilizadas no projeto sobre o lixo, gostaria de problematizar a representatividade dos atores sociais (moradores) nas discussões estabelecidas sobre o tema. Nos relatos da professora, pude perceber que houve intenção de envolver a comunidade no projeto, porém passo a questionar como se deu tal inserção, pois na perspectiva de análise que assumo, não poderia deixar de questionar e colocar em discussão o comportamento simbólico e cotidiano desta comunidade em relação ao lixo. Ao questionar a inserção dos atores sociais (moradores) no projeto, busco aporte nas teorizações dos Estudos Culturais que, por sua vez, chamam a atenção para as práticas mais ordinárias da vida cotidiana, desde a forma como as pessoas selecionam e arranjam os objetos em suas moradias, como compram, o que comem (FISKE, 1992 apud NELSON; TREICHLER; GROSSBERG, 2002) e, nesse caso, como descartam e acondicionam o seu lixo. Compreender a forma de acondicionamento e descarte do lixo como um comportamento imanente à cultura desta comunidade direciona nosso olhar para uma análise sob o viés das tradições dos Estudos Culturais, pois, "a cultura é entendida tanto como uma forma de vida - compreendendo ideias, atitudes, linguagens, práticas, instituições e estruturas de poder - quanto toda uma gama de práticas culturais: formas, textos, cânones, arquitetura, mercadorias produzidas em massa, e assim por diante.” (ibidem, p.14).

Creio que, nesse caso, podemos utilizar uma analogia com os estudos de Hall (1997) a respeito da construção e da circulação do significado, para compreender melhor esta argumentação. O "lixo" está no mundo como resultado das ações humanas, independente da descrição que fazemos dele. Entretanto, a identificação que fazemos dele só é possível devido a uma forma particular que utilizamos para classificar e, consequentemente, de atribuir significado ao mesmo. Portanto, há diferentes formas e sistemas de significação para o "lixo" que devem ser compreendidos como produto 
resultante da forma como ele é socialmente construído através da linguagem 4 e da representação. Estou assinalando que a nossa percepção daquilo que consideramos "lixo" está profundamente marcada por estruturações estéticas e culturais que permitem estabelecer o que ver, como ver e o que fazer com este "lixo". Nesse sentido, dar voz aos atores sociais (moradores), discutir e refletir sobre a construção social/cultural/histórica das práticas de acondicionamento do lixo e seus significados, talvez pudesse colocá-los na posição de participantes interessados/as no projeto desenvolvido pela escola, talvez pudessem ser descritos/as como parte de uma "comunidade de consciência ampliada5". Faço tais considerações partindo dos relatos que surgiram, tanto nas narrativas da professora - "É claro que nem todos conseguiram convencer seus pais (...) Confesso que me deu vergonha, pois no projeto, eles também instruíram as merendeiras e não estava funcionando. (...) Profe, mas se eles não aprenderam, nós temos que dar o exemplo mostrando como se faz." - , como na fala de uma aluna, durante a saída de campo de Geografia - "Continua tudo igual como a gente viu com a profe de Ciências! Não muda nada!".

Parece-me que a "verdade" formada no interior do discurso científico ocupa lugar de destaque nas práticas discursivas e intervenções que configuram as abordagens, naquela escola, sobre o lixo, tanto com os alunos como com a comunidade do bairro. Dessa forma, algumas proposições da Corrente Científica de Educação Ambiental perpassam o trabalho desta professora. De acordo com Sauvé (2005, p.23), nessa corrente a "perspectiva é a de compreender melhor para orientar melhor a ação", integrando-se com o enfoque e o processo de resolução de problemas (proposição da Corrente Resolutiva). Quando a professora busca oferecer um "aprofundamento" do trabalho a partir da busca de conhecimentos técnico/científicos sobre o lixo, não estaria intencionando "compreender melhor para orientar melhor a ação"?

\subsection{CONSIDERAÇÕES FINAIS}

Ao pensar na centralidade dada a determinadas abordagens e pressupostos teóricos da Educação Ambiental, que identifiquei nas cenas pedagógicas analisadas, encontro um determinado tipo de educador, constituído na imanência de um

\footnotetext{
${ }^{4}$ A partir da virada cultural, a linguagem passa a ser compreendida como algo mais amplo, "surge um interesse na linguagem como um termo geral para as práticas de representação, sendo dada à linguagem uma posição privilegiada na construção e circulação do significado.” (HALL, 1997, p.28)

${ }^{5} \mathrm{O}$ termo é de Jacqueline Bobo (NELSON; TREICHLER; GROSSBERG, 2002, p. 33).
} 
domínio de conhecimento, fortemente marcado pelas Ciências Naturais. Entendo as práticas pedagógicas como estratégias direcionadas à constituição de um tipo de aluno e por que não um sujeito/aluno/ecológico?6 Faço essas considerações por acreditar ser relevante colocar questões de fundo no cruzamento entre práticas discursivas e subjetividades na pauta das discussões pedagógicas, principalmente as direcionadas à Educação Ambiental, pois assim como Carvalho (2008), compreendo a Educação Ambiental como propulsora na formação do sujeito ecológico. Contudo, ao colocar seus alunos em "encontros com o mundo", os professores não possuem "garantia" nem controle dos resultado/efeitos que tais experiências possam desencadear, pois a experiência é algo ligado diretamente ao sujeito, como algo que lhe passa (LAROSSA, 2001), provocando percepções e sentidos - uma operação essencialmente individual, uma apropriação pessoal dos significados -, que como venho discutindo no decorrer das minhas análises, se dá no interior da cultura, imbricada por relações de poder e saber.

O convite que este texto faz é para que nós - professores/educadores (ambientais) -, olhemos para o complexo terreno da produção do nosso entendimento e das possibilidades de significação da Educação Ambiental. Terreno que sabemos ser rico - polimorfo e polissêmico -, e mesmo assim, não oferece "garantia" de dar conta de todos os sentidos possíveis que uma realidade possa vir a ter. Dessa forma, analisar o processo de enunciação que engendra as práticas pedagógicas, ditas ambientais, que atravessam o cotidiano de uma instituição escolar é uma forma de tentar mapear um dos muitos caminhos dessa produção de sentidos sobre a Educação Ambiental. Penso que assim, talvez, possamos nos comprometer politicamente com análises sobre as formas como a cultura engendra diferentes processos de produção de significados sobre as questões ambientais. Gostaria, então, de encerrar minhas reflexões (que considero provisórias e possíveis de mudança), com as palavras de Flickinger (1994, p. 198):

A sensação de desamparo profundo, frente à falta de fundamentos suficientes para uma prática educacional, dirigida para conscientização em relação aos problemas ambientais está omnipresente. Por isso, não se pode esperar de ninguém uma solução rápida do impasse; deveríamos, no entanto, tentar, num

\footnotetext{
${ }^{6}$ Busco com o termo "sujeito/aluno/ecológico" uma aproximação com as teorizações de Carvalho (2008), que define o sujeito ecológico como: um tipo ideal de sujeito, enquanto uma identidade narrativa ambientalmente orientada, capaz de encarar os dilemas societários, éticos e estéticos configurados pela crise societária em sua perspectiva cultural; comprometido com um projeto de sociedade socialmente emancipada e ambientalmente sustentável. Tal aproximação me faz pensar na possibilidade de articulação destas concepções com o mundo da escola.
} 
esforço comum, contribuir com alguns elementos no mosaico cuja a forma final não pode ser antecipada.

\subsection{REFERÊNCIAS}

CALDEIRA, T. P. R. A presença do autor e a pós-modernidade em antropologia. Novos Estudos CEBRAP. São Paulo, v.21. p.133-157, 1988.

CARVALHO, I. C. M. A invenção ecológica: narrativas e trajetórias da educação ambiental no Brasil. 3. ed. Porto Alegre: UFRGS, 2008.

FLICKINGER, H. G. O ambiente epistemológico da Educação Ambiental. Educação \& Realidade, Ética e Educação Ambiental. Porto Alegre: FACED/UFRGS, v.19, n.2, jul./dez. 1994. p.197-2007.

FOUCAUlT, M. Microfísica do Poder. 25. ed. Tradução por Roberto Machado. Rio de Janeiro: Edições Graal, 2008.

A verdade e as formas jurídicas. Rio de Janeiro: Nau, 1999, 160 p.

GEERTZ, C. Estar lá, escrever aqui. Diálogos. São Paulo, v.22, n.3, p.58-63, 1989.

GOTTSCHALK, S. Postmodern Sensibilities and Ethnographia Possibilities. In: BANKS, A; BANKS, S.P. Fiction and social research: by ice or fire. London: Altamira Press, 1998. p. 206-226.

HALL, S. A centralidade da cultura: notas sobre as revoluções de nosso tempo. Educação \& Realidade. Cultura, mídia e educação. Porto Alegre: FACED/UFRGS, v.22, n.2, jul./dez. 1997. p. $15-46$.

LARROSA,J. Notas sobre a experiência e o saber de experiência. Campinas: Leituras SME, 2001.

LYOTARD, J. F. A condição pós-moderna. 10 ed. Tradução por Ricardo Corrêa Barbosa. Rio de Janeiro: José Olympio, 2008.

MACHADO, R. Introdução: Por uma genealogia do poder. In: FOUCAULT,M. Microfísica do Poder. 25. ed. Tradução por Roberto Machado. Rio de Janeiro: Edições Graal, 2008.

MOMO, M. Mídia e consumo na produção de uma infância pós-moderna que vai à escola. Porto Alegre: PPG-Educação/UFRGS. Tese de Doutorado. 2007.

NELSON,C.; TREICHLER,P. A.; GROSSBERG,L. Estudos Culturais: uma introdução. In: Silva, T. T. (org. e trad.) Alienígenas na sala de aula. 4. ed. Petrópolis: Vozes, 2002. p.7-38.

SAUVÉ, L. Uma cartografia das correntes em educação ambiental. In: SATO, M.;

CARVALHO, I. C. M. (orgs.) Educação ambiental: pesquisa e desafios. Porto Alegre: Artmed, 2005. p. 17-44. 
TAVARES, M. T. G. Uma escola: texto e contexto. In: GARCIA, R. L. (Org.). Método: pesquisa com o cotidiano. Rio de Janeiro: DP\&A, 2003. p.43-62. TRAVASSOS, E.G. A prática da educação ambiental nas escolas. Porto Alegre: Mediação, 2006.

VEIGA-NETO, A. Olhares. In: COSTA, M. V. (Org.). Caminhos investigativos: novos olhares na pesquisa em educação. 2. ed. Rio de Janeiro: DP\&A, 2002. p.23-38. 